\title{
EDITORIAL
}

\section{Recuperar la iniciativa}

Era l'any 1966 i el panorama de la música popular va canviar completament. En aquell any, es va establir el cànon d'excel·lència en relació amb el so de la contemporaneïtat. Les referències són incomptables i, per no allargar-ho, un podria quedar-se només amb tres, a saber, el Pet Sounds, dels Beach Boys; el Revolver, dels Beatles; y el Blonde on Blonde, de Bob Dylan. Segurament, es tracta de les referències més significatives de tres dels artistes més influents en la definició del paisatge sonor del present. Alguna cosa estava canviant, ho feia ràpidament i feia en el plànol més determinant, la història de les mentalitats.

Aquell entorn cultural va ser el caldo de cultiu del que havia de ser la reacció social davant de la crisi ambienta. Va ser en aquell moment en el que es va definir el sentit $i$ l'orientació d'una política ambiental — d'allà sorgiria el primer codi ambiental, això és la National Environmental Protection Act (1969), aprovada tres anys després; així com el ferment intel·lectual per a la Conferència d'Estocolm (1972), que, amb el pas del temps fa més gran el seu llegat rupturista, sobretot, en comparació amb el discurs molt més complaent i contingut d'El futur que volem, document final de la Conferència de Rio +20 , hereva d'aquell primer encontre-.

Efectivament, amb el pas dels anys, la radicalitat de la preocupació i la resposta social davant de la crisi ambiental, la gran crisi civilitzatòria de la Modernitat, han estat domesticades mitjançant el llit de Procust del llenguatge diplomàtic, en el context de múltiples acords multilaterals en matèria ambiental que han anat entrant en vigor des d'aleshores; del desenvolupament del Dret ambiental a través de regulacions detallistes i tecnicistes que cada vegada semblen més susceptibles de ser capturades pels actors econòmics més implicats en la degradació ambiental; i, finalment, la marginació de la preocupació pel medi ambient i l'explotació de maneres diferents de reproducció social en el marc, primer, de la financiarització de l'economia global i, després, en el context de la crisi econòmica profunda generada per l'esmentada financiarització.

Vist amb la perspectiva d'aquell llunyà 1966 — cinquanta anys han passat des d'aleshores - , podria dir-se que s'ha perdut la innocència i que la resposta a la crisi ambiental s'ha convertit en un expedient purament tècnic que simplifica problemes 
complexos i profunds mitjançant anàlisis senzilles d'eficiència, de cost-benefici. Aquesta captura de la preocupació per la degradació del medi ambient, que era també una preocupació per la banalització, l'estandardització i la mercantilització de les condicions de vida dels éssers humans per part dels sistemes institucionals hegemònics, ha anat teixint un discurs oficial que, emparat en el mantra del desenvolupament sostenible, ha desactivat el potencial de canvi social que s'apuntava en l'alba de les preocupacions ambientals que es percebia en la segona meitat dels seixanta.

La crisi ambiental s'inscrivia en el marc d'una resposta alternativa als esquemes de dominació, basats en el paradigma dualista de la Modernitat, que havien donat lloc als diferents models d'economia capitalista, de mercat o d'estat, que degradaven, al mateix temps, l'espai físic i el cultural. La reconducció de la crisi civilitzatòria a un expedient tècnic mostra fins a quin punt els elements hegemònics de l'economia-món capitalista han assumit la iniciativa i configuren els sistemes globals de governança, erosionant les idees més fonamentals del Dret ambiental a través de la seva canalització mitjançant regulacions aparentment neutres, provinents de l'episteme dominat, que justifiquen $\mathrm{i}$ legitimen la continuació dels mecanismes usuals d'explotació (ambiental i humana) a través d'un llenguatge pretesament tècnic i avaloratiu.

El camí recorregut entre les esperances encara inconcretes de 1966 i la seva formalització tècnica a partir de la noció de desenvolupament sostenible, desplegada a partir de l'Informe Brundtland (1987), és la història d'un fracàs, les conseqüències del qual poden rastrejar-se fins al moment present, en què les limitacions del sistema institucional global per produir una resposta valenta i apropiada davant de la qüestió del canvi climàtic són posades de manifest per la pal·lidesa i fragilitat de l'Acord de París, al que dedicàvem l'editorial del número anterior. Efectivament, el procés de desregulació i financiarització de l'economia global iniciat en els anys setanta, justament davant dels dubtes plantejats des de diferents discursos alternatius en la dècada anterior, ha culminat en la domesticació de la problemàtica ambiental i la preservació de les relacions de poder en el marc de l'economia-món capitalista. La pressió sobre la perifèria, les dinàmiques d'injustícia que venen emparades pel sistema $\mathrm{i}$ la persistència de la degradació ambiental venen posades de manifestes per la victimització dels defensors ambientals, cada vegada més vulnerables, com mostra l'augment dels que han estat assassinats, assetjats o amenaçats en els darrers anys. 
La violació dels drets humans en relació amb la protecció del medi ambient, així com la persistència i creixement de la injustícia ambiental en el plànol global, posen de manifest la colonització per part dels actors hegemònics de l'economia capitalista dels discursos rupturistes vinculats a la crisi ambiental que van començar a desplegar-se en els anys seixanta. En aquest sentit, davant de la incertesa en relació amb els efectes de l'ús i la capacitat tecnològica desenvolupada per l'espècie humana en les seves mateixes condicions de vida, s'imposa un discurs tecnocràtic, més o menys actualitzat, que promou dinàmiques neocolonials i l'explotació persistent de la natura, sense prestar atenció al deteriorament de les condicions de vida, ja no de les comunitats locals afectades, sinó de la humanitat en conjunt. Els drets humans, la justícia ambiental i el principi de precaució com a matriu bàsica per a la presa de decisions perden nitidesa davant dels discursos tecnocràtics i economicistes que combinen l'apel·lació a la sortida de la crisi amb el negacionisme més cras.

Per tot això, val la pena que no només des del punt de vista dels moviments socials, sinó també des de la comunitat professional i acadèmica del Dret ambiental, es recuperi la iniciativa en el disseny d'un discurs més respectuós amb la naturalesa, així com més sensible als més desfavorits en el repartiment dels beneficis i perjudicis derivats del metabolisme social de l'economia-món capitalista. En aquest sentit, l'aferrament a textures lingüístiques purament tecnocràtiques, limitades a la legalitat més estricta $\mathrm{i}$ banal, acaba constituint una legitimació dels desequilibris generats en el marc del sistema vigent de reproducció social, insistint en el caràcter salvífic de la tecnologia, en l'acceptació de l'autocomplaença pròpia de la societat de consum i en la justificació de les estructures organitzatives del capitalisme global.

En aquest sentit, en la comunitat del Dret ambiental, seria benvingut un discurs crític, que ja s'intenta per part de molts professionals i acadèmics, que hauria de donar lloc a l'apoderament dels actors del sistema habilitats per al control del poder en el marc dels moltíssims microconflictes que contribueixen a dibuixar un panorama general certament descoratjador. Per això, segurament convé reforçar la idea dels principis ambientals com a paràmetres de control dels poders públics i, en aquesta línia, proporcionar musculatura argumentativa als tribunals per avançar en la concreció d'una fiscalització efectiva d'uns poders públics representatius massa sovint capturats pels actors favorables a perseverar en els desequilibris del sistema, tant des del punt de vista de la justícia, com des del punt de vista de la sostenibilitat. 
Potser la innocència d'aquells que, al 196, captaven les limitacions del discurs salvífic de la societat de consum i la tecnocràcia pot ser inspiradora en un moment en què, essent evident l'encapsulament de la problemàtica ambiental per part dels llenguatges i els actors hegemònics, les injustícies ambientals i les pràctiques insostenibles troben emparament, justificació i fins i tot estímul. Potser les pàgines d'aquesta Revista puguin servir per encoratjar, avançar i aprofundir el debat, en un moment en què es fa necessària la recuperació de la iniciativa per armar sòlidament i pragmàtica un discurs ambientalista efectiu que interpel·li els actors jurídics en el control dels poders, moltes vegades opacs, que persisteixen en les dinàmiques de degradació del medi ambient $\mathrm{i}$ despossessió dels menys afavorits. 


\section{EDITORIAL}

\section{Recuperar la iniciativa}

Era 1966 y el panorama de la música popular cambió completamente. En aquel año, se estableció el canon de la excelencia en relación con el sonido de la contemporaneidad. Las referencias son incontables y, para no alargarlo, uno podría quedarse sólo con tres, a saber, el Pet Sounds, de los Beach Boys; el Revolver, de los Beatles; y el Blonde on Blonde, de Bob Dylan. Seguramente, se trata de las referencias más significativas de tres de los artistas más influyentes en la definición del paisaje sonoro del presente. Algo estaba cambiando, lo hacía rápidamente y lo hacía en el plano más determinante, la historia de las mentalidades.

Aquel entorno cultural fue el caldo de cultivo de lo que había de ser la reacción social ante la crisis ambiental. Fue en aquel momento en el que se definió el sentido y la orientación de una política ambiental — de ahí surgiría el primer código ambiental, esto es la National Environmental Protection Act (1969), aprobada tres años después; así como el fermento intelectual para la Conferencia de Estocolmo (1972), que, con el paso del tiempo agiganta su legado rupturista, sobre todo, en comparación con el discurso mucho más complaciente y contenido de El futuro que queremos, documento final de la Conferencia de Rio+20, heredera de aquél primer encuentro-.

Efectivamente, con el paso de los años, la radicalidad de la preocupación y la respuesta social ante la crisis ambiental, la gran crisis civilizatoria de la Modernidad, han sido domesticadas a través del lecho de Procusto del lenguaje diplomático, en el contexto de los múltiples acuerdos multilaterales en materia ambiental que han ido entrando en vigor desde entonces; el desarrollo del Derecho ambiental a través de regulaciones detallistas y tecnicistas que cada vez aparecen como más susceptibles de ser capturadas por los actores económicos más implicados en la degradación ambiental; y, finalmente, la marginación de la preocupación por el medio ambiente y la exploración de modos distintos de reproducción social en el marco, primero, de la financiarización de la economía global y, después, en el contexto de la crisis económica profunda generada por la mencionada financiarización.

Visto con la perspectiva de aquel lejano 1966 — 50 años han pasado desde entoncespodría decirse que se ha perdido la inocencia y que la respuesta a la crisis ambiental se 
ha convertido en un expediente puramente técnico que simplifica problemas complejos y profundos mediante sencillos análisis de eficiencia, de coste-beneficio. Esta captura de la preocupación por la degradación del medio ambiente, que era también una preocupación por la banalización, estandarización y mercantilización de las condiciones de vida de los seres humanos por parte de los sistemas institucionales hegemónicos, ha ido tejiendo un discurso oficial que, amparado en el mantra del desarrollo sostenible, ha desactivado el potencial de cambio social que se apuntaba en el amanecer de las preocupaciones ambientales que se percibía en la segunda mitad de los años sesenta.

La crisis ambiental se inscribía en el marco de una respuesta alternativa a los esquemas de dominación, basados en el paradigma dualista de la Modernidad, que habían dado lugar a los diferentes modelos de economía capitalista, de mercado o de estado, que degradaban, al mismo tiempo, el espacio físico y el cultural. La reconducción de la crisis civilizatoria a un expediente técnico muestra hasta qué punto los elementos hegemónicos de la economía-mundo capitalista han asumido la iniciativa y configuran los sistemas globales de gobernanza, erosionando las ideas más fundamentales del Derecho ambiental a través de su canalización mediante regulaciones aparentemente neutras, provenientes de la episteme dominante, que justifican y legitiman la continuación de los mecanismos usuales de explotación (ambiental y humana) a través de un lenguaje pretendidamente neutro y avalorativo.

El camino recorrido entre las esperanzas aún inconcretas de 1966 y su formalización técnica a partir de la noción de desarrollo sostenible, desplegada a partir del Informe Brundtland (1987), es la historia de un fracaso, cuyas consecuencias pueden rastrearse hasta el momento presente, en que las limitaciones del sistema institucional global para producir una respuesta valiente y apropiada ante la cuestión del cambio climático son puestas de manifiesto por la palidez y la fragilidad del Acuerdo de París, al que dedicábamos el editorial del número anterior. Efectivamente, el proceso de desregulación y financiarización de la economía global iniciado en los años setenta, justamente ante las dudas planteadas desde diferentes discursos alternativos en la década anterior, ha culminado en la domesticación de la problemática ambiental y la preservación de las relaciones de poder en el marco de la economía-mundo capitalista. La presión sobre la periferia, las dinámicas de injusticia que vienen amparadas por el sistema y la persistencia en la degradación ambiental vienen puestas de manifiesto por 
la victimización de los defensores ambientales, cada vez más vulnerables, como muestra el aumento de los que han sido asesinados, acosados o amenazados en los últimos años.

La violación de los derechos humanos en relación con la protección del medio ambiente, así como la persistencia y crecimiento de la injusticia ambiental en el plano global, ponen de manifiesto la colonización por parte de los actores hegemónicos de la economía capitalista de los discursos rupturistas vinculados a la crisis ambiental que empezaron a desplegarse en los años sesenta. En este sentido, ante la incertidumbre en relación con los efectos del uso de la capacidad tecnológica desarrollada por la especie humana en sus propias condiciones de vida, se impone un discurso tecnocrático, más o menos actualizado, que promueve dinámicas neocoloniales y la explotación persistente de la naturaleza, sin prestar atención al deterioro de las condiciones de vida, ya no de las comunidades locales afectadas, sino de la humanidad en su conjunto. Los derechos humanos, la justicia ambiental y el principio de precaución como matriz básica para la toma de decisiones pierden nitidez ante los discursos tecnocráticos y economicistas que combinan la apelación a la salida de la crisis con el negacionismo más craso.

Por todo ello, vale la pena que no sólo desde el punto de vista de los movimientos sociales, sino también desde la comunidad profesional y académica del Derecho ambiental, se recupere la iniciativa en el diseño de un discurso más respetuoso con la naturaleza, así como más sensible a los más desfavorecidos en el reparto de los beneficios y perjuicios derivados del metabolismo social de la economía-mundo capitalista. En este sentido, el apego a texturas lingüísticas puramente tecnocráticas, limitadas a la legalidad más estricta y banal, acaba constituyéndose en una legitimación de los desequilibrios generados en el marco del sistema vigente de reproducción social, insistiendo en el carácter salvífico de la tecnología, en la aceptación de la autocomplacencia propia de la sociedad de consumo y en la justificación de las estructuras organizativas del capitalismo global.

En este sentido, en la comunidad del Derecho ambiental, sería bienvenido un discurso crítico, que ya se intenta por parte de muchos profesionales y académicos, que debería redundar en el apoderamiento de los actores del sistema habilitados para el control del poder en el marco de los muchísimos microconflictos que contribuyen a dibujar un panorama global ciertamente desolador. Por ello, seguramente conviene reforzar la idea de los principios ambientales como parámetros de control de los poderes públicos y, en esta línea, proporcionar musculatura argumentativa a los tribunales para avanzar en la 
concreción de una fiscalización efectiva de unos poderes públicos representativos demasiado a menudo capturados por los actores favorables a perseverar en los desequilibrios del sistema, tanto desde el punto de vista de la justicia, como desde el punto de vista de la sostenibilidad.

Quizá la inocencia de aquéllos que, en 1966, captaban las limitaciones del discurso salvífico de la sociedad de consumo y la tecnocracia puede ser inspiradora en un momento en que, siendo evidente el encapsulamiento de la problemática ambiental por parte de los lenguajes y los actores hegemónicos, las injusticias ambientales y las prácticas insostenibles encuentran amparo, justificación y hasta estímulo. Quizá las páginas de esta Revista puedan servir para animar, avanzar y profundizar el debate, en un momento en que se hacen necesaria la recuperación de la iniciativa para armar sólida y pragmáticamente un discurso ambientalista efectivo que interpele a los actores jurídicos en el control de los poderes, muchas veces opacos, que persisten en las dinámicas de degradación del medio ambiente y desposesión de los menos favorecidos. 